COVID-19

\title{
Suspension laryngoscopy-assisted percutaneous dilatational tracheostomy: a safe method in COVID-19
}

\section{Tracheotomia percutanea dilatativa in laringoscopia in sospensione nei pazienti affetti da COVID-19}

\author{
Franco Parmigiani ${ }^{1}$, Antonello Alberto Sala², Cristiana Fumanti', Andrea Luigi Rescaldani', Federico Giuseppe Quarta', \\ Stefano Carlo Paradisi ${ }^{1}$ \\ ${ }^{1}$ Otorhinolaryngology Unit, Azienda Socio-Sanitaria Territoriale - (ASST) della Brianza, Vimercate (MB), Italy; ${ }^{2}$ Anesthesiology Unit, \\ Azienda Socio-Sanitaria Territoriale - (ASST) della Brianza, Vimercate (MB), Italy
}

\section{SUMMARY}

Objective. COVID-19 respiratory insufficiency has augmented demand of tracheostomies in intubated patients. Herein, we analyse our experience with suspension laryngoscopyassisted percutaneous dilatational tracheostomy (SL-PDT) to assess the safety for both healthcare personnel and patients.

Methods. We conducted a retrospective review of all patients who underwent SL-PDT in the Intensive Care Unit (ICU) between March 13 and April 17, 2020 (first peak of SARSCoV-2 pandemic).

Results. We included 28 SL-PDTs conducted in the ICU by a single operator using standard personal protective equipment (PPE) for high-risk procedures. The average procedure time was 30 minutes. Intraoperative complications were few, mild and promptly resolved. No operators were infected after the procedure.

Conclusions. SL-PDT is a safe and quick technique: it is preferable to open surgical procedures, where air-flow cessation cannot be achieved and droplet emission is high. The cost/benefit ratio is low. A disadvantage is the need for an ENT surgeon who is familiar with direct laryngoscopy, with the main difficulty being the exposure of the upper airways. Minimal air leakage and good control of occasional bleeding makes it a safe procedure for the patient and medical personnel alike.

KEY WORDS: tracheostomy, laryngoscopy, SARS-CoV-2, COVID-19, safety

\section{RIASSUNTO}

Obiettivo. L'insufficienza respiratoria causata da COVID-19 ha incrementato la richiesta di tracheostomie nei pazienti intubati. Abbiamo analizzato la nostra esperienza con la Tracheostomia Dilatativa Percutanea sotto controllo in Laringoscopia Diretta in Sospensione (SL-PDT) per valutarne la sicurezza per il personale sanitario coinvolto ed i pazienti.

Metodi. Abbiamo condotto uno studio retrospettivo dei pazienti sottoposti a SL-PDT in Terapia Intensiva tra il 13 marzo e il 17 aprile 2020 (primo picco della pandemia da SARSCoV-2).

Risultati. Abbiamo incluso 28 SL-PDT realizzate come procedura mono-operatore dotato di Dispositivi di Protezione Individuale (DPI) per procedure ad alto rischio. Le complicanze intraoperatorie erano esigue, di grado lieve e prontamente risolte. Nessun operatore ̀̀ risultato infetto dopo la procedura.

Conclusioni. SL-PDT è una tecnica sicura e veloce, preferibile a procedure chirurgiche in cui non è possibile spegnere la ventilazione e l'emissione di aerosol è elevata. Il rapporto costi/benefici è basso. Richiede un chirurgo ORL avvezzo alla laringoscopia diretta, essendo la difficoltà principale l'esposizione delle vie aeree superiori. La minima perdita di aria e l'agevole controllo dell'eventuale sanguinamento la rendono una procedura sicura per $i$ professionisti coinvolti.

PAROLE CHIAVE: tracheotomia, laringoscopia, SARS-CoV-2, COVID-19, sicurezza
Received: January 14, 2021

Accepted: May 17, 2021

\section{Correspondence}

Federico Giuseppe Quarta

Otorhinolaryngology Unit, Azienda Socio-Sanitaria

Territoriale - (ASST) della Brianza, via Santi Cosma e Damiano 10, 20871 Vimercate (MB), Italy

Tel. +390396657577

E-mail: federico.quarta@unimi.it

Funding

None.

Conflict of interest

The Authors declare no conflict of interest.

\begin{abstract}
How to cite this article: Parmigiani F, Sala AA, Fumanti C, et al. Suspension laryngoscopy-assisted percutaneous dilatational tracheostomy: a safe method in COVID-19. Acta Otorhinolaryngol Ital 2021;41:389-394. https://doi. org/10.14639/0392-100X-N1435
\end{abstract}

() Società Italiana di Otorinolaringoiatria e Chirurgia Cervico-Facciale

\section{cc) (1) $\ominus$}

This is an open access article distributed in accordance with the CC-BY-NC-ND (Creative Commons Attribution-NonCommercial-NoDerivatives 4.0 International) license. The article can be used by giving appropriate credit and mentioning the license, but only for non-commercial purposes and only in the original version. For further information: https:// creativecommons.org/licenses/by-nc-nd/4.0/deed.en 


\section{Introduction}

Pneumonia caused by Coronavirus Disease 2019 (COVID-19) can cause in a number of cases a rapid progression to acute respiratory distress syndrome (ARDS): it is characterised by respiratory failure and can lead to death if mechanical ventilation procedures are not promptly performed. The high rates of hospital and intensive care unit (ICU) admissions during the virus outbreak resulted in serious congestion in hospitals and extreme measures were taken to avoid collapse of healthcare services. Patients who need prolonged sedation and intubation in the ICU often require safer and easier airway management, such as tracheostomy ${ }^{1}$.

A recent study revealed that early tracheostomy (i.e., performed within the first 10 days after orotracheal intubation) is associated with a reduction in mechanical ventilation duration, mortality rate and length of stay in the ICU ${ }^{2}$. However, during surgical tracheostomy procedures the risk of exposure of healthcare personnel to COVID-19 is high ${ }^{3}$. Surgical tracheostomies place surgeons in the highest risk category along with ICU nurses and anesthesiologists, because direct access to the airway and mechanical ventilation generate considerable quantities of droplets when air leaks from the tube cuff ${ }^{4}$. Other bedside techniques have the same problem (e.g., Rapitrac, Fantoni) ${ }^{5,6}$. We reviewed the limited data and found no clear evidence in favour of one technique over another from the standpoint of viral spread and protection for healthcare professionals.

At our institution, we routinely adopt suspension laryngoscopy-assisted percutaneous dilatational tracheostomy (SLPDT) ${ }^{7,8}$ on sedated and intubated patients and believe that it may be preferable to open tracheostomy and percutaneous cricothyrotomy ${ }^{9}$, where air-flow cessation is not possible and droplet emission is inevitably higher. Two critically important preoperative criteria for SL-PDT are: 1) the ability to hyperextend the neck and 2) the presence of at least $1 \mathrm{~cm}$ between the cricoid cartilage and suprasternal notch, ensuring that the patient will be amenable to reintubation in case of accidental extubation.

We experienced a large augmentation of demand for tracheostomy in patients intubated in the ICU during the first SARS-CoV-2 outbreak in 2020. In this study, we analyse our experience with SL-PDT.

\section{Materials and methods}

The study is designed as a retrospective review. Due to its retrospective design, it did not need approval from Azienda Socio-Sanitaria Territoriale (ASST) della Brianza Institutional Ethics Committee.

We retrospectively evaluated the charts of all COVID-19 patients, hospitalised and intubated in the ICU during the first SARS-CoV-2 outbreak beginning in late February 2020. We selected all patients who underwent tracheostomy during their ICU stay and we included 28 cases. These interventions took place between March 13 to April 17, 2020 and in all cases we performed SL-PDT.

SL-PDT was chosen because: 1) its external-internal path (rather than the other way around) reduces potential viral spread from the trachea; 2) we wanted to minimise changes in the tracheostomy tube during recovery in, or after discharge from, the ICU (i.e., in the hospital ward); 3) there are few complications; 4) we had previous experience with its use in ICU patients.

As previously described by Sharp and Castellanos ${ }^{8}$, the patient is positioned and prepped in the same way as for standard operative tracheostomy. With the patient under general anaesthesia and intubated with an oro-tracheal tube, the operator is positioned at the head of the ICU bed. The laryngoscope is placed just into the laryngeal inlet within the aperture of the false vocal folds. The position of the laryngoscope is then secured and the patient's head is stabilised with the suspension apparatus. This manoeuver allows the surgeon to aspirate secretions under laryngoscopic view and to obtain a good vision of the tracheal walls for the subsequent steps. The laryngeal tube cuff is moved in the lower part of the trachea: in this way the tube cuff is protected from rupture during the procedure and the lower airways, where the viral load is maximum, are separated from the operators. We routinely use a single dilator Ciaglia Blue Rhino Percutaneous Tracheostomy Introducer Kit (Cook Critical Care Inc, Bloomington, Indiana, USA) or Portex ULTRAperc Single Stage Dilator Technique Kit (Smiths Medical MD Inc, Minneapolis, Minnesota, USA). After having palpated the anatomical landmarks (suprasternal notch, first tracheal rings and cricoid cartilage), the operator makes a transcervical puncture in the intercartilaginous space between the second and third tracheal ring, having caution to remain in the midline of the neck in order to avoid piercing anterior venous vessels. The continuous vision of the anterior wall of the trachea through the laryngoscope also allows good control of transcervical puncture of the trachea from the inside of the airways (Fig. 1) and subsequent positioning of the guidewire (Fig. 2) ${ }^{10}$. In addition, the surgical laryngoscope bears suspension of the laryngeal box, increasing the rigidity of the tracheal compartment. This facilitates all dilatation manoeuvers with the ventilation tube in place (Figs. 3, 4). Two small horizontal cutaneous cuts are made at each side of the dilator to make insertion easier. We do not use flexible bronchoscopes.

After dilatation, we insert the tracheostomy cannula (Fig. 5); once the initial part is visible, the mechanical ventilation is held for the time of exchange of the ventila- 


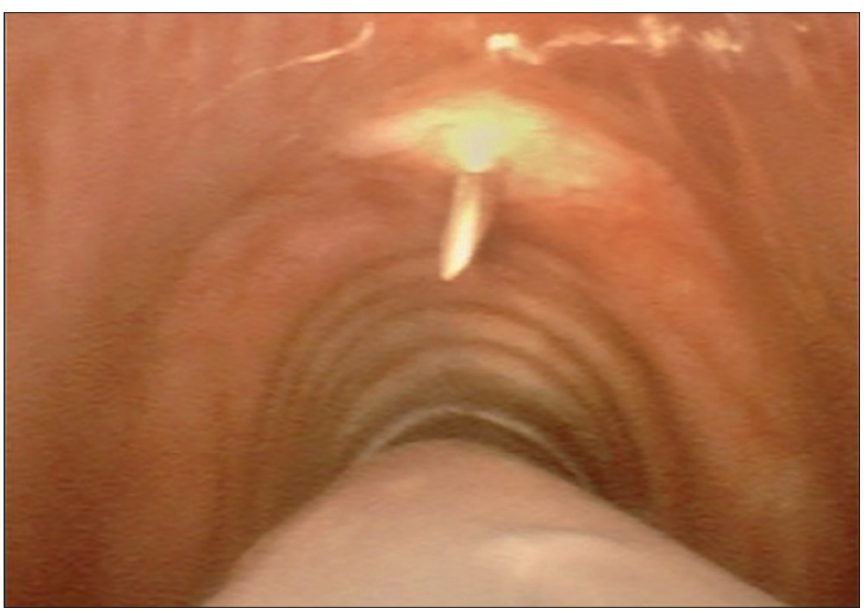

Figure 1. Insertion of the guide needle. Dislocation of the orotracheal tube downward.

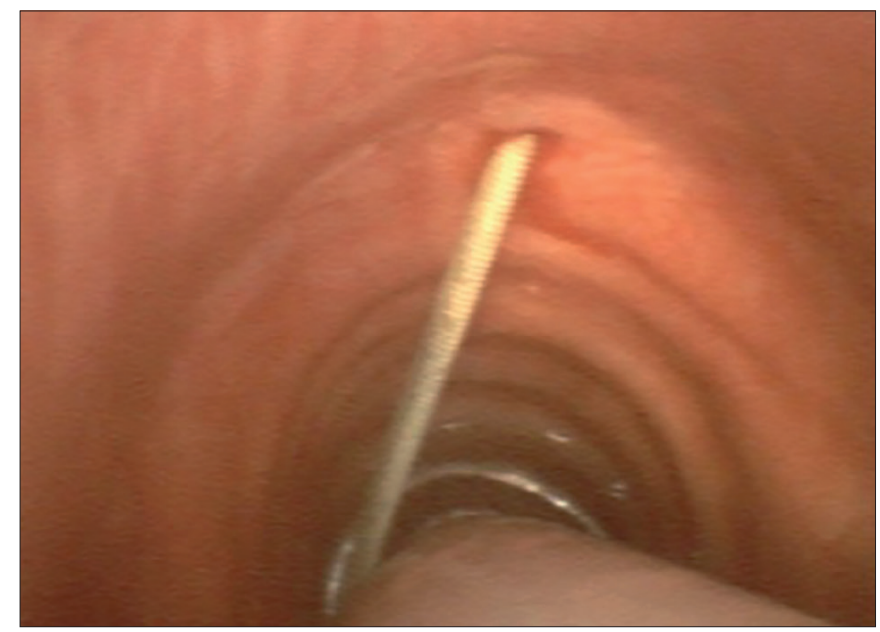

Figure 2. Positioning of the guidewire.

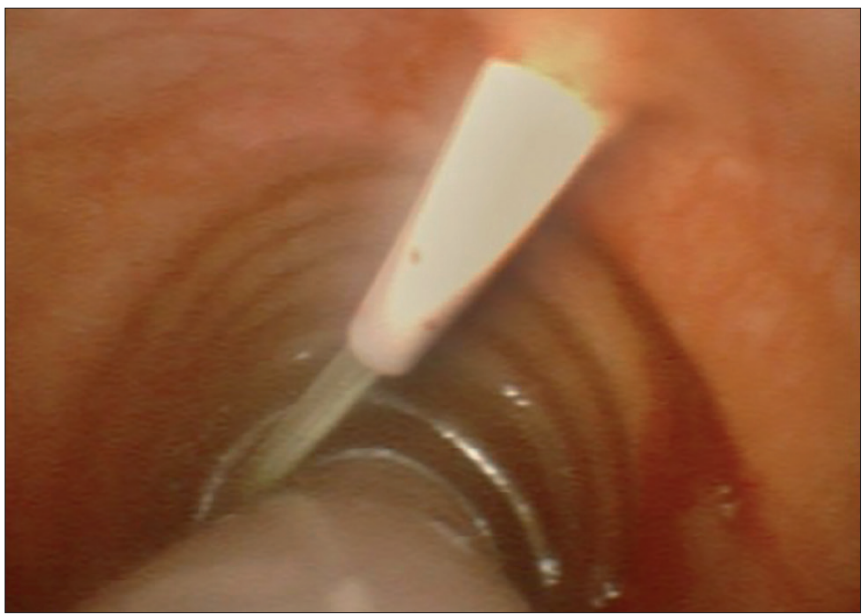

Figure 3. Insertion of the first part of dilator.

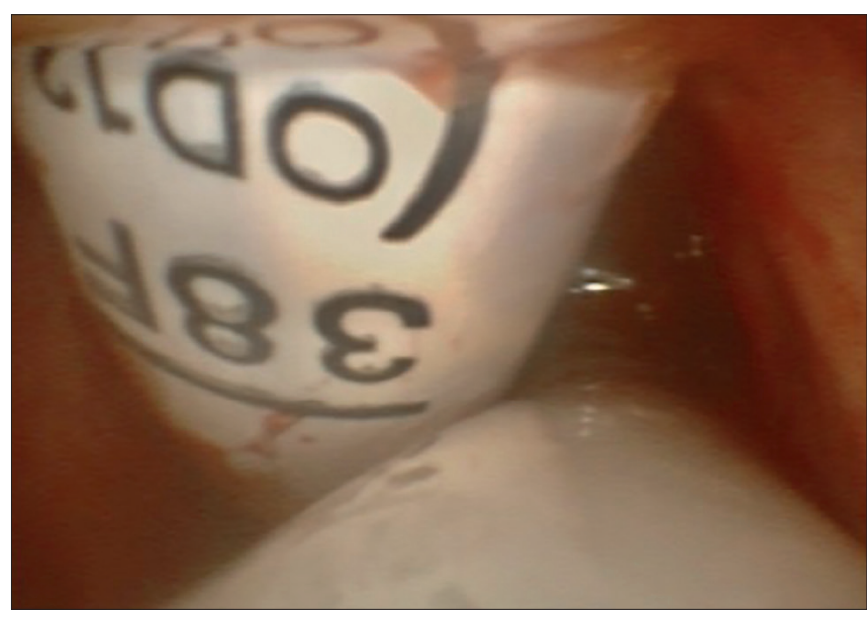

Figure 4. Introduction of the final part of dilator.

tion tubes: the endotracheal tube is pulled out, the operator adjusts the final position of the cannula and then connects it with the ventilation circuit; only during this step is the airway open.

\section{Results}

From March 13 to April 17, 2020, we performed 28 SLPDTs, 15 of which were performed within the first 3 weeks of the outbreak, during maximum ICU use (Tab. I).

All SL-PDTs were conducted in the ICU by an ear, nose and throat surgeon using standard personal protective equipment (PPE) for high-risk procedures (i.e., N95/FFP2 mask, double gloves, shoe covers, disposable protective uniform, and ventilated helmet with a frontal light). All the procedures were conducted with the assistance of the patient's ICU nurse: the intensivist attended in case of particularly fragile patients who needed close monitoring. The average procedure time was 30 minutes (range: 20-50 minutes).

In our series, there were 26 males and 2 females (M:F ratio, 13:1); the mean age was 62 years (range: $50-76$ years) and the average time from ICU admission to tracheostomy was 10 days (range: 5-19 days).

All patients received heparin (low-molecular-weight-heparin, LMWH, or ultrafractionated heparin, UH) at prophylactic or therapeutic dosages: in 5 cases patients were receiving continuous venovenous haemodialysis (CVVHD). During the procedures we experienced 4 minor haemorrhagic complications $(14.3 \%)$ : these consisted in mild subdermal bleeding resulting from the skin incision made to facilitate dilator and cannula insertion and were promptly resolved with bipolar coagulation (two cases) or gauze package dressing (two cases). Only in one case (3.6\%) was a major haemorrhagic complication experienced (a large 


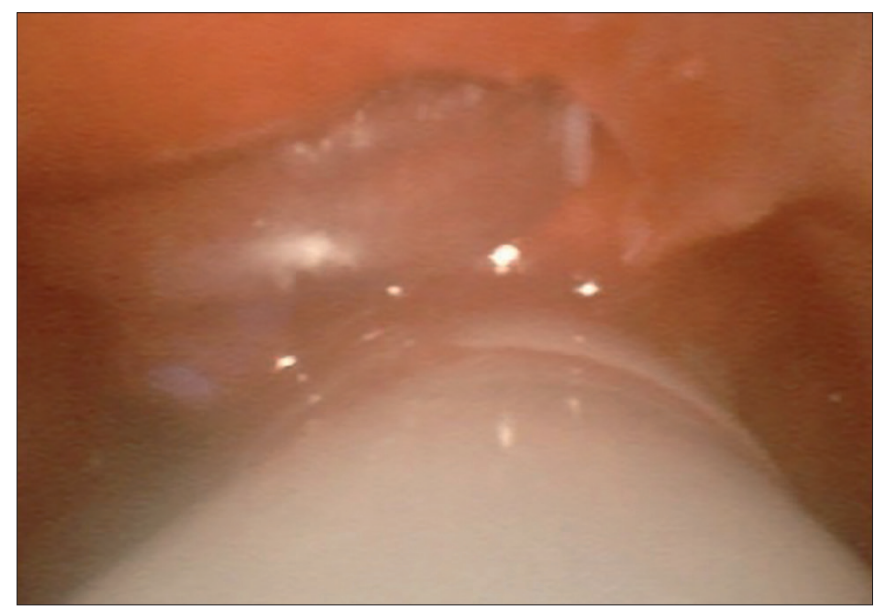

Figure 5. Introduction of the cannula tip. Only in this moment the orotracheal tube is removed.

haematoma resulting from the lesion of a venous vessel of the anterior part of the neck) and required abortion of the percutaneous procedure and conversion to open cervicotomy for control of haemostasis: eventually we proceeded with surgical tracheostomy.

The cannula did not need to be changed in any patient, either during recovery in the ICU or hospital ward, and excellent adherence between the skin and cannula avoided the air leaks generating aerosol and thus facilitating viral diffusion. No difficulties in care in medium or mild care units were reported. In all cases, the tracheostomy was removed 3 days before discharge.

No surgeon, anaesthesiologist or nurse present at the procedures had symptoms of COVID-19 disease during subsequent weeks, none had SARS-CoV-2 antibodies by serological test conducted by the Hospital Preventive Healthcare Service during the month of May 2020.

\section{Discussion}

The outbreak of SARS-CoV-2 has reached worldwide proportions since it began in late 2019. Since mid-February 2020, Italy has been one of the leading nations in the world for infections.

According to official online data of the first peak of pandemic, roughly $10 \%$ of the Italians who were infected were health-care workers ${ }^{11}$.

Tracheostomy is a routine procedure in critically-ill patients who require an extended period on mechanical ventilation and can facilitate weaning from ventilation and potentially increase the availability of ICU beds ${ }^{12}$.

During the first peak of the COVID-19 pandemic, ICUs experienced a massive influx of patients worldwide who were critically ill, many of whom became candidates for trache- ostomy. However, due to the direct access to the airway and mechanical ventilation, which generates the spread of a large amount of droplets in case of air-leakage from the tube cuff, tracheostomies expose surgeons to high risk of contagion, along with with ICU nurses and anaesthesiologists.

From open surgical procedures to percutaneous dilatational systems, there are different techniques commonly used to perform a tracheostomy in critically-ill patients. After a review of the available literature, there are no clear data to establish the superiority of one approach over another from the standpoint of infectious transmission or safety: operators should continue to do tracheostomies using the techniques and equipment with which they are familiar, confident and experienced in using ${ }^{12}$.

At our institution, SL-PDT is a commonly used technique to perform tracheostomy in sedated and intubated patients in ICU.

This technique permits to broaden the field of application of percutaneous dilatational tracheostomy (PDT), because it can overcome some classical contraindications to traditional percutaneous technique, such as unsafe airway, emergency, presence of a median cervical lesion, non-palpable cricoid cartilage, obese and overweight patients and coagulopathy. SL-PDT is a reasonable alternative to open tracheostomy in patients who need prolonged ventilation secondary to ARDS, but some conditions make them unsuitable candidates for traditional percutaneous tracheostomy ${ }^{13}$.

As other techniques of PDT, it can be carried out as a bedside procedure, eliminating the need to transfer the patient in the operating room $(\mathrm{OR})$, which is difficult and dangerous. In fact, due to the fragility of these patients for the acute illness, a transfer to the OR needs to be accompanied by the complex anaesthesia system and ventilator machine and expose all personnel involved to the risk of contamination.

PDT and SL-PDT share some advantages over conventional surgical tracheostomy: it is easier to perform and with shorter operative time, lower risk of intra- and postoperative bleeding, reduced risk of infection of the surgical site, lower costs and reduced time of spontaneous tracheostomy stoma closure after decannulation ${ }^{13,14}$.

In order to reduce the complication rates, PDT is performed under flexible endoscopic control of a bronchoscope usually passed through the orotracheal tube. However, in a patient with high ventilation demands and complicated ventilator settings such as in COVID-19, the use of a flexible endoscope can lead to ventilatory compromise secondary to partial obstruction of the tube and difficulties in maintaining adequate PEEP and/or minute ventilation ${ }^{7,13}$.

In SL-PDT, the need for endoscopic control during the procedure is eliminated by direct vision through the laryngo- 
Table I. SL-PDT performed in ICU from March 13 to April 17, 2020.

\begin{tabular}{|c|c|c|c|c|c|c|}
\hline Gender & Age & $\begin{array}{l}\text { Date of ICU } \\
\text { admission }\end{array}$ & $\begin{array}{c}\text { Date of } \\
\text { tracheostomy }\end{array}$ & $\begin{array}{c}\text { Type of } \\
\text { tracheostomy }\end{array}$ & Anticoagulation & Complications \\
\hline M & 72 & 02-Mar & 13-Mar & SL-PDT & LMWH therapeutic & None \\
\hline M & 58 & 09-Mar & 16-Mar & SL-PDT & LMWH prophylactic & None \\
\hline M & 59 & 05-Mar & 16-Mar & SL-PDT & LMWH therapeutic & None \\
\hline M & 73 & 03-Mar & 18-Mar & SL-PDT & LMWH prophylactic & None \\
\hline M & 54 & 08-Mar & 20-Mar & SL-PDT & UH (CVHD) & None \\
\hline M & 51 & 08-Mar & 20-Mar & SL-PDT & UH (CVHD) & None \\
\hline $\mathrm{F}$ & 72 & 15-Mar & 23-Mar & SL-PDT & LMWH therapeutic & None \\
\hline M & 59 & 17-Mar & 24-Mar & SL-PDT & LMWH therapeutic & None \\
\hline M & 74 & 12-Mar & 24-Mar & SL-PDT & LMWH therapeutic & None \\
\hline M & 67 & 09-Mar & 25-Mar & SL-PDT & LMWH prophylactic & None \\
\hline $\mathrm{F}$ & 56 & 14-Mar & 25-Mar & SL-PDT & UH & None \\
\hline M & 50 & 18-Mar & 26-Mar & SL-PDT & LMWH therapeutic & Bleeding \\
\hline M & 62 & 22-Mar & 27-Mar & SL-PDT & UH & None \\
\hline M & 59 & 19-Mar & 27-Mar & SL-PDT & LMWH therapeutic & None \\
\hline M & 52 & 23-Mar & 30-Mar & SL-PDT & LMWH therapeutic & None \\
\hline M & 61 & 24-Mar & 01-Apr & SL-PDT & UH & None \\
\hline M & 55 & 13-Mar & 02-Apr & SL-PDT & LMWH prophylactic & None \\
\hline M & 57 & 26-Mar & 02-Apr & SL-PDT & LMWH therapeutic & None \\
\hline M & 76 & 17-Mar & 02-Apr & SL-PDT & UH (CVHD) & Bleeding \\
\hline M & 61 & 01-Apr & 06-Apr & SL-PDT & LMWH prophylactic & Bleeding \\
\hline M & 68 & 28-Mar & 06-Apr & SL-PDT & UH (CVHD) & None \\
\hline M & 55 & 29-Mar & 06-Apr & SL-PDT & UH (CVVHD) & None \\
\hline M & 61 & 30-Mar & 07-Apr & SL-PDT & LMWH therapeutic & None \\
\hline M & 65 & 27-Mar & 08-Apr & SL-PDT, converted OPEN & LMWH therapeutic & Haematoma \\
\hline M & 72 & 24-Mar & 08-Apr & SL-PDT & LMWH prophylactic & None \\
\hline M & 73 & 04-Apr & 16-Apr & SL-PDT & LMWH therapeutic & Bleeding \\
\hline M & 63 & 10-Apr & 16-Apr & SL-PDT & LMWH therapeutic & None \\
\hline M & 61 & 05-Apr & 17-Apr & SL-PDT & LMWH therapeutic & None \\
\hline
\end{tabular}

SL-PDT: suspension laryngoscopy-assisted percutaneous dilatational tracheostomy; CVWH: continuous venovenous haemodialysis; LMWH: low molecular weight heparin; UH: unfractioned heparin.

scope: this permits excellent vision which helps in seeing palpation on the anterior tracheal wall and visualisation of the planned puncture site, while reducing to a minimum the risk of posterior tracheal wall injury.

Thanks to the suspension system, the airway is rigidly fixed in place while being lifted and extended anteriorly, improving identification and palpation of anatomical airway landmarks. This makes SL-PDT a good alternative even in overweight and obese patients, which have very short, thick necks and challenging airway access, traditionally a contraindication to $\mathrm{PDT}^{7,8,15}$.

SL-PDT can be performed in patients with bleeding disorders defined as INR $>1.5$ or platelet count $<50,000 / \mathrm{mm}^{3}$, patients treated with heparin either at prophylactic or therapeutic dosages or receiving CVVHD. This is particularly important in patients hospitalised for COVID-19 pneumo- nia, in which anticoagulation is a mainstay in current management. In these conditions, the operative setting of the laryngeal suspension system allows easy control of haemostasis in case of endotracheal bleeding with the possibility to use rigid suction instruments, mechanical pressure and monopolar or bipolar coagulation devices ${ }^{13,14}$.

The only complications observed in our study were intraoperative bleedings. These consisted primarily in small cutaneous bleedings from the skin incision made to facilitate dilator and cannula insertion, which are easily controlled with electrocautery or mechanical compression. The dilatational technique, thanks to the insertion of dilators with progressively greater diameter and the tracheostomy cannula, achieves haemostasis on the involved tissues during these manoeuvers.

In our experience, after transcervical puncture and progres- 
sive dilatation, a large haematoma of the anterior part of the neck developed in one case: we decided to abort the percutaneous procedure and convert to an open cervicotomy. Once control of bleeding was achieved, we performed a traditional surgical tracheostomy. It is important to consider that during all procedures the endotracheal tube maintained its position away from the surgical field, without any risk of premature extubation for the patient, and not exposing healthcare personnel to any leakage of potentially infectious ventilation circuit.

Another advantage of the technique assisted by laryngoscopic control is the possibility to evaluate the airways preoperatively: once the laryngoscope is positioned into the laryngeal inlet, it is possible to discover and treat potential damages to the laryngotracheal system caused by the prolonged period of intubation.

In our opinion, SL-PDT is preferable to open tracheostomy and percutaneous cricothyrotomy, where air-flow cessation is not possible and droplet emission is inevitably higher. Although surgical tracheostomy remains viable in some patients ${ }^{12}$, the cost/benefit ratio for direct laryngoscopy to perform SL-PDT is low; the advantages include the singleoperator nature of the procedure, lack of requirement for a flexible bronchoscope (resulting in less structural damage and low-cost sterilisation and acquisition), safety and rapidity and easy management of the rigid instrumentation used.

The major disadvantage of the procedure is that it requires an experienced ENT surgeon who is familiar with direct laryngoscopy procedures, the main difficulty being the exposure of the upper airways in an ICU bed.

The only absolute contraindications to the proposed technique are severe trismus, unstable cervical spine (fractures, hernias, syringomyelia, etc.) ${ }^{16}$ and other anatomical conditions that do not allow good visualisation of the laryngeal plane.

\section{Conclusions}

The COVID-19 pandemic required a new approach to care for ICU patients to reduce the length of stay and complications. SL-PDT is an excellent tracheostomy technique in patients intubated for SARS-CoV-2 disease and can be preferable due to its various advantages over traditional techniques: it is a bedside and single-surgeon procedure; it is easy and quick to perform, without increased risk for complications; it can be carried out in practically any patient, even if obese or on anticoagulant therapy; it is a safe method in terms of potential viral spread, preventing exposure of healthcare personnel.

\section{References}

1 Freeman BD, Isabella K, Lin N, et al. A meta-analysis of prospective trials comparing percutaneous and surgical tracheostomy in critically ill patients. Chest 2000;118:1412-1418. https://doi.org/10.1378/ chest.118.5.1412

2 Rosano A, Martinelli E, Fusina F, et al. Early percutaneous tracheostomy in coronavirus disease 2019: association with hospital mortality and factors associated with removal of tracheostomy tube at ICU discharge. A cohort study on 121 patients. Crit Care Med 2021;49:261270. https://doi.org/10.1097/CCM.0000000000004752

3 Pichi B, Mazzola F, Bonsembiante A, et al. CORONA-steps for tracheotomy in COVID-19 patients: a staff-safe method for airway management. Oral Oncol 2020;105:104743. https://doi.org/10.1016/j. oraloncology.2020.104682

4 Westphal K, Byhahn C, Wilke HJ, et al. Percutaneous tracheostomy: a clinical comparison of dilatational (Ciaglia) and translaryngeal (Fantoni) techniques. Anesth Analg 1999;89:938-943. https://doi. org/10.1097/00000539-199910000-00022

5 Schachner A, Ovil Y, Sidi J, et al. Percutaneous tracheostomy a new method. Crit Care Med 1989;17:1052-1056. https://doi. org/10.1097/00003246-198910000-00017

6 Rao BK, Pande R, Sharma SC, et al. Percutaneous tracheostomy. Ann Card Anaesth 2003;6:19-26.

7 White HN, Sharp DB, Castellanos PF. Suspension laryngoscopyassisted percutaneous dilatational tracheostomy in high-risk patients. Laryngoscope 2010;120:2423-2429. https://doi.org/10.1002/ lary. 21019

8 Sharp DB, Castellanos PF. Clinical outcomes of bedside percutaneous dilatational tracheostomy with suspension laryngoscopy for airway control. Ann Otol Rhinol Laryngol 2009;118:91-98. https://doi. org/10.1177/000348940911800203

9 Heikkinen M, Aarnio P, Hannukainen J. Percutaneous dilational tracheostomy or conventional surgical tracheostomy? Crit Care Med 2000;28:1399-1402. https://doi. org/10.1097/00003246-200005000-00023

10 Peris A, Linden M, Pellegrini G, et al. Percutaneous dilatational tracheostomy: a self-drive control technique with video fiberoptic bronchoscopy reduces perioperative complications. Minerva Anestesiol 2009;75:21-25.

11 Task force COVID-19 del Dipartimento Malattie Infettive e Servizio di Informatica, Istituto Superiore di Sanità. (2020, April 7). Sorveglianza Integrata COVID-19 in Italia. https://www.epicentro.iss.it/coronavirus/bollettino/Infografica_7aprile\%20ITA.pdf.

12 Brass P, Hellmich M, Ladra A, et al. Percutaneous techniques versus surgical techniques for tracheostomy. Cochrane Database Syst Rev 2016;7:CD008045. https://doi.org/10.1002/14651858.CD008045.pub2

13 Moulin M, Aboussouan MP, Castellanos PD, et al. Evaluation of percutaneous dilatational tracheostomy under laryngosuspension. Eur Arch Otorhinolaryngol 2020;277:3391-3396. https://doi.org/10.1007/ s00405-020-06141-1

14 Moulin M, Castellanos PF, Atallah I. Suspension laryngoscopyassisted percutaneous dilatational tracheostomy. Eur Ann Otorhinolaryngol Head Neck Dis 2021;138:53-55. https://doi.org/10.1016/j. anorl.2020.06.024

15 Blankenship DR, Kulbersh BD, Gourin CG, et al. High-risk tracheostomy: exploring the limits of the percutaneous tracheostomy. Laryngoscope 2005;115:987-989. https://doi.org/10.1097/01. MLG.0000163107.80668.12

16 Ben Nun A, Orlovsky M, Best LA. Percutaneous tracheostomy in patients with cervical spine fractures - feasible and safe. Interact Cardiovasc Thorac Surg 2006;5:427-429. https://doi.org/10.1510/ icvts.2005.125690 